\title{
Evaluation of Patients Undergoing Continuous Renal Replacement Therapy Due to Acute Kidney Injury in Our Pediatric Intensive Care Unit
} \author{
Aysun Karabay Bayazit ${ }^{2}$ \\ ${ }^{1}$ Department of Pediatric Intensive Care, Faculty of Medicine, Cukurova University \\ ${ }^{2}$ Department of Pediatric Nephrology, Faculty of Medicine, Cukurova University \\ ${ }^{3}$ Department of Pediatrics, Faculty of Medicine, Cukurova University
}

Nagehan Aslan ${ }^{1 *}$, Dincer Yildizdas', Bahriye Atmis², Ozden Ozgur Horoz ${ }^{1}$, Zeliha Haytoglu ${ }^{3}$, Engin Melek ${ }^{2}$ and

Submission: October 03, 2019; Published: October 21, 2019

*Corresponding author: Nagehan Aslan, Department of Pediatric Intensive Care, Faculty of Medicine, Cukurova University, Turkey

\begin{abstract}
Aim: Acute kidney injury is a frequent clinical condition in critically ill pediatric patients. At the present time secondary reasons of acute renal injury stands out in pediatric intensive care units and mortality rates reaches to $50 \%$. In our study we aimed to evaluate clinical outcomes and treatment modalities of critically ill children with acute kidney injury who applied continuous renal replacement therapy in a tertiary pediatric intensive care.
\end{abstract}

Material and methods: The patients who had acute kidney injury because various reasons and applied continuous renal replacement therapy between March 2017 and September 2018 in our unit included the study retrospectively. We recorded patient's information and continuous renal replacement therapy modality information.

Results: The study included 26 patients. The most detected acute kidney injury reason was sepsis (38.5\%). The most common CRRT indication was fluid overload (84.6\%). The most used vascular access site was internal jugular vein (73\%). Mortality detected in 4(15.3\%) patients. Vasoactive inotropic score was significantly higher $(\mathrm{p}=0,013)$ and the time between hospitalization and CRRT starting was significantly longer $(p=0,014)$ in mortality group. Mean fluid overload was $\% 9,05 \pm 4,98$. We detected a positive, significant correlation between fluid overload and PRISM III score ( $r=0,557, p=0,003)$. The filter life was longer in the heparin used group as an anticoagulant $(\mathrm{p}<0.001, \mathrm{p}=0.018)$.

Conclusion: Continuous renal replacement therapy is commonly use in acute renal injury treatment because of steady fluid removal and maintain acid-base homeostasis in treatment of fluid overload and acute renal injury in critically ill children.

Keywords: Acute renal injury; Pediatric intensive care; Continuous renal replacement therapy; Fluid overload

\section{Introduction}

Recently, the secondary causes of acute kidney injury (AKI) such as sepsis, congenital heart disease, and nephrotoxic drug use have come into prominence more than the primary renal disease in the etiology of AKI in patients treated in pediatric intensive care units [1]. Secondary AKI in critical pediatric patients is often associated with multiple organ failure and has a course with a mortality rate of up to $40-50 \%[2,3]$. AKI is one of the risk factors for development of chronic kidney disease. Because of this reason, early diagnosis and appropriate management of the AKI is important in terms of preventing poor clinical course and preventing chronic kidney disease [4]. With technological advances and the development of easy-to-use devices, continuous renal replacement therapy (CRRT) has become widely used in patients with hemodynamically unstable conditions because of maintaining continuous fluid withdrawal and electrolyte balance in the treatment of fluid overload and AKI [5-8]. Although there are still divergencies related to definite indications of CRRT and the ideal start time, CRRT has become a preferred modality in the treatment of AKI not only in adults but also in pediatric intensive care patients and infants under $10 \mathrm{~kg}$ with its safe use and proven efficacy $[9,10]$. In this study, the aim is to evaluate the demographic characteristics, clinical outcomes, and treatment modalities of patients undergoing CRRT due to AKI in our pediatric intensive care unit.

\section{Materials and Methods}

In this study, the patients who were under 18 years of age, developed AKI for various reasons and underwent CRRT, and 
hospitalized in our tertiary care pediatric intensive care unit between March 2017 and September 2018 were included prospectively. Patients who underwent CRRT for metabolic disease, hyperammonaemia and patients with chronic kidney disease were excluded from the study. Acute kidney injury staging was performed according to the 'Kidney Disease Improving Global Outcomes' (KDIGO) guidelines [11]. Patients' information [age, gender, cause of AKI, PRISM-III score, creatine, glomerular filtration rate (GFR), percentage of fluid overload, vascular access way, catheter size, mechanical ventilation, vasoactive inotropic score (VIS), time between intensive care hospitalization and CRRT, length of ICU stay, anticoagulant use and mortality] and information on the CRRT model applied [CRRT modality (continuous venovenous hemofiltration (CVVH), continuous venovenous hemodiafiltration: CVVHDF, continuous venovenous hemodialysis: CVVHD), membrane brand (Prismaflex HF20, M60, M100, M150), membrane surface area (m2), membrane type (Polyarylethersulfone (PAES), Acrylonitrile (ANE69)), number of filters used, filter life] were recorded. Patients' hemodialysis catheters were placed percutaneously by pediatric intensive care minors, with the guidance of the ultrasound or using the blind method. Femoral, internal jugular and subclavian veins were used for catheterization. In patients without contraindications (activated coagulation time (ACT) $<200 \mathrm{sec}$, aPTT60 sec, INR2,5, platelet count $50,000 / \mathrm{mm} 3$ ) standard heparin was applied for filter anticoagulation, and the dose of heparin Results

Table 1: The demographics and clinical characteristics of patients who underwent CRRT

\begin{tabular}{|c|c|}
\hline & $\mathrm{n}=26$ \\
\hline Age* (Month) $^{*}$ & 57 \\
\hline Weight* (kg) & $19,6(4-70)$ \\
\hline PRISM III score** & $24 \pm 6,8$ \\
\hline Male Gender (n, \%) & $15(48)$ \\
\hline $\begin{array}{c}\text { AKI cause } \\
\text { Cardiac } \\
\text { Sepsis/Septic Shock } \\
\text { Tumor Lyzis Syndrome } \\
\text { Rabdomyolyzis } \\
\text { Hemolytic Uremic Syndrome } \\
\text { Hipovolemic Acute Tubuler Necrosis } \\
\text { Drug Intoxication }\end{array}$ & $\begin{array}{c}3(11,5) \\
10(38,5) \\
2(7,7) \\
2(7,7) \\
5(19,2) \\
3(11,5) \\
1(3,9)\end{array}$ \\
\hline $\begin{array}{c}\text { AKI Stage (n, \%) } \\
\text { Stage } 2 \\
\text { Stage } 3\end{array}$ & $\begin{array}{c}4(\% 15) \\
22(\% 85)\end{array}$ \\
\hline GFR* (\%) & $26,6(6,4-97)$ \\
\hline Fluid Overload $* *(\%)$ & $9,05 \pm 4,98$ \\
\hline Creatine Level at Admission* (mg/dL) & $1,3(0,3-17)$ \\
\hline Creatine Level at CRRT Initiation* (mg/dL) & $2,3(0,8-17)$ \\
\hline Time between PICU Admission and CRRT Initiation* (day) & $2(0-24)$ \\
\hline CRRT Duration* (day) & $4(1-12)$ \\
\hline Length of Stay in PICU* (day) & $11,5(3-81)$ \\
\hline \multicolumn{2}{|l|}{ Vascular Access Site (n, \%) } \\
\hline Femoral & $3(11,6)$ \\
\hline
\end{tabular}

was titrated in a way to keep the ACT between 180-220 sec. Continuous renal replacement therapy was performed with the Prismaflex system(Baxter $®$ ) and Dialisan(Baxter $®$ ) was used as replacement, dialysate and predilution fluid. The percentage of fluid overload in the last 24 hours was calculated using the formula [(Total taken fluid-total extracted fluid)/body weight at admission x100] [12]. Vasoactive inotropic score was calculated using the formula=Dopamine dose $(\mu \mathrm{g} / \mathrm{kg} / \mathrm{min})+$ dobutamine dose $(\mu \mathrm{g} / \mathrm{kg} / \mathrm{min})+100 \times$ Epinephrine dose $(\mu \mathrm{g} / \mathrm{kg} / \mathrm{min})+10$ $\times$ Milrinone dose $(\mu \mathrm{g} / \mathrm{kg} / \mathrm{min})+10,000 \times$ Vasopressin dose $(\mathrm{U} /$ $\mathrm{kg} / \mathrm{min})+100 \times$ Norepinephrine dose $(\mu \mathrm{g} / \mathrm{kg} / \mathrm{min})[13]$. For the study, the approval was obtained from the clinical trials ethics committee of University Faculty of Medicine.

\section{Statistical analysis}

IBM SPSS Statistics Version 20.0 package program was used for the statistical analysis of the data. Categorical measurements were summarized as numbers and percentages, and numerical measurements were summarized as mean and standard deviation (median and largest-smallest where necessary). The Kolmogorov Smirnov test was used to test whether the numerical measurements provided the normal distribution assumption. In order to evaluate the correlation between numerical measurements, Pearson Correlation coefficient and related $\mathrm{p}$ value were obtained. The level of statistical significance in all tests was taken as 0.05 . 


\section{Journal of Anesthesia \& Intensive Care Medicine}

\begin{tabular}{|c|c|c|}
\hline Internal Jugular & \multicolumn{2}{|c|}{$19(73)$} \\
\hline Subklavian & \multicolumn{2}{|c|}{$4(15,4)$} \\
\hline \multicolumn{3}{|l|}{ Catheter Size (n, \%) } \\
\hline $7 F$ & \multicolumn{2}{|c|}{$4(15)$} \\
\hline $8 F$ & \multicolumn{2}{|c|}{$4(15)$} \\
\hline 9F & \multicolumn{2}{|c|}{$11(43)$} \\
\hline $12 F$ & \multicolumn{2}{|c|}{$7(27)$} \\
\hline $\begin{array}{c}\text { CRRT Modality (n, \%) } \\
\text { SVVHDF } \\
\text { SVVHD } \\
\end{array}$ & \multicolumn{2}{|c|}{$\begin{array}{c}25(96,2) \\
1(3,8)\end{array}$} \\
\hline \multirow{4}{*}{$\begin{array}{c}\text { Membran Brand (n, \%) and Surface Area }\left(\mathrm{m}^{2}\right) \\
\text { Prismaflex HF20 } \\
\text { Prismaflex M60 } \\
\text { Prismaflex M100 } \\
\text { Prismaflex M150 }\end{array}$} & $9(35)$ & 0,2 \\
\hline & $10(38)$ & 0,6 \\
\hline & $6(23)$ & 0,9 \\
\hline & $1(4)$ & 1,5 \\
\hline $\begin{array}{c}\text { Membran Type (n, \%) } \\
\text { PAES } \\
\text { ANE69 }\end{array}$ & \multicolumn{2}{|c|}{$\begin{array}{c}9(35) \\
17(65)\end{array}$} \\
\hline Filter Life* (saat) & \multicolumn{2}{|c|}{$29,5(6-46)$} \\
\hline Number of Filters $* *$ & \multicolumn{2}{|c|}{$9 \pm 4,9$} \\
\hline Vasoactive Inotropic Score* & \multicolumn{2}{|c|}{$24(0-53)$} \\
\hline Mechanical Ventilation (n, \%) & \multicolumn{2}{|c|}{$17(65,4)$} \\
\hline Mortality (n, \%) & \multicolumn{2}{|c|}{$4(15,4)$} \\
\hline
\end{tabular}

Table 2: Comparison of mortality and without mortality groups.

\begin{tabular}{|c|c|c|c|}
\hline & $\begin{array}{c}\text { Mortality Group } \\
\mathrm{n}=4 \\
\text { Mean } \pm \text { SD } \\
\text { Median (min-max) }\end{array}$ & $\begin{array}{l}\text { Without Mortality Group } \\
n=22 \\
\text { Mean } \pm \text { SD } \\
\text { Median (min-max) }\end{array}$ & $\mathbf{p}$ \\
\hline Age (Month) & $\begin{array}{c}95 \pm 51,02 \\
94(8-144)\end{array}$ & $\begin{array}{c}89,09 \pm 79,6 \\
56,5(5-212) \\
\end{array}$ & 0,69 \\
\hline Weight (kg) & $\begin{array}{c}28,7 \pm 27,9 \\
17,5(10-70)\end{array}$ & $\begin{array}{c}24,24 \pm 18,87 \\
19,6(4-66)\end{array}$ & 0,67 \\
\hline GFR (\%) & $\begin{array}{c}46,9 \pm 11,29 \\
44,2(36,6-62,8)\end{array}$ & $\begin{array}{c}30,4 \pm 25,1 \\
18,8(6,4-97)\end{array}$ & 0,08 \\
\hline PRISM III Score & $\begin{array}{c}26,2 \pm 2,75 \\
26,5(23-29)\end{array}$ & $\begin{array}{c}23,63 \pm 7,37 \\
23,5(11-39)\end{array}$ & 0,318 \\
\hline Fluid Overload (\%) & $\begin{array}{c}9,67 \pm 2,16 \\
9,85(7-12) \\
\end{array}$ & $\begin{array}{c}8,9 \pm 5,3 \\
10(0-20)\end{array}$ & 0,776 \\
\hline Creatine Level at Admission & $\begin{array}{l}0,97 \pm 0,46 \\
1(0,4-1,4)\end{array}$ & $\begin{array}{c}2,81 \pm 3,68 \\
1,5(0,3-17)\end{array}$ & 0,319 \\
\hline Creatine Level at CRRT Initiation & $\begin{array}{c}1,82 \pm 0,57 \\
1,75(1,3-2,5) \\
\end{array}$ & $\begin{array}{c}3,69 \pm 3,49 \\
2,3(0,8-17) \\
\end{array}$ & 0,155 \\
\hline Vasoactive Inotropic Score & $\begin{array}{c}41,5 \pm 7,93 \\
39(35-53) \\
\end{array}$ & $\begin{array}{l}16 \pm 18,11 \\
6,5(0-53)\end{array}$ & 0,013 \\
\hline CRRT Duration (day) & $\begin{array}{l}8,25 \pm 5,18 \\
10(1-12)\end{array}$ & $\begin{array}{l}4,5 \pm 1,81 \\
4(2-10)\end{array}$ & 0,128 \\
\hline Time between PICU Admission-CRRT Initiation (day) & $\begin{array}{c}10 \pm 9,89 \\
6,5(3-24)\end{array}$ & $\begin{array}{l}2,32 \pm 3,8 \\
1(0-18)\end{array}$ & 0,014 \\
\hline Lenght of Stay in PICU (day) & $\begin{array}{c}20,25 \pm 13,96 \\
14(12-41)\end{array}$ & $\begin{array}{c}19,5 \pm 19,6 \\
9(3-81)\end{array}$ & 0,354 \\
\hline
\end{tabular}

A total of 26 patients were included in the study and the median age was 57 months (5-212). The most common AKI cause was sepsis (38.5\%). Twenty-two (84.6\%) of the patients had stage
3 AKI. The most common indication for CRRT was fluid overload in $22(84.6 \%)$ patients, while it was electrolyte imbalance in 3 $(11.5 \%)$ patients and drug intoxication in $1(3.8 \%)$ patient. Twenty- 
five (96\%) patients underwent CVVHDF. The most commonly used vascular access way was internal jugular vein (73\%). Median CRRT duration was 4 days (1-12) and median intensive care unit stay time was 11.5 days (3-81) (Table 1). Mortality was detected in $4(15.3 \%)$ patients. No significant difference detected between the groups with mortality and without mortality in terms of age, body weight, GFR, creatine values at admission and onset of CRRT, PRISM III score, percentage of fluid overload, duration of CRRT, length of intensive care stay (Table 2). Sixteen of the patients $(61.5 \%)$ were receiving vasoactive inotrope support and $17(65.3 \%)$ were on mechanical ventilators. In the group with mortality, VIS was significantly higher $(p=0.013)$ and the duration between hospitalization and CRRT was significantly longer $(p=0.014)$. PRISM III score was higher in the group with mortality than that in the group without mortality, however, it was not statistically significant $(\mathrm{p}=0.318)$. In the correlation analysis, a statistically significant positive correlation between mortality and VIS ( $\mathrm{r}=0.486, \mathrm{p}=0.012)$ and CRRT duration $(\mathrm{r}=0.486, \mathrm{p}=0.012)$ was detected. However, it was found that mortality increased with the increase in the time between hospitalization and CRRT ( $\mathrm{r}=0.500, \mathrm{p}=0.09)$. CRRT duration was found to be increased with higher VIS $(r=0.442, p=0.024)$. A positive, significant correlation was found between the percentage of fluid overload and the PRISM III score ( $\mathrm{r}=0.557, \mathrm{p}=0.003)$. Mean fluid overload of patients was $9.05 \% \pm 4.98$. Twelve of the patients $(46.1 \%)$ had coagulation abnormalities and therefore anticoagulants could not be administered. In the group in which heparin was used as the anticoagulant, filter life was longer, and the number of filters was less ( $\mathrm{p}<0.001, \mathrm{p}=0.018$ ) (Table 3).

Table 3: Comparison of groups with and without heparin as anticoagulation.

\begin{tabular}{|c|c|c|c|}
\hline & $\begin{array}{c}\text { Heparin Group } \\
\text { Mean } \pm \text { SD }\end{array}$ & $\begin{array}{c}\text { Without Heparin } \\
\text { Group Mean } \pm \text { SD }\end{array}$ & p \\
\hline $\mathrm{n}(\%)$ & $14(54)$ & $12(46)$ & \\
\hline Filter Life (saat) & $36 \pm 5,2$ & $14,2 \pm 3,4$ & $<0,001$ \\
\hline $\begin{array}{c}\text { Number of } \\
\text { Filters }\end{array}$ & $3,2 \pm 1,4$ & $4,5 \pm, 1,1$ & 0,018 \\
\hline
\end{tabular}

\section{Discussion}

Acute kidney injury is a sudden renal dysfunction due to decreased renal perfusion and is a condition with urgent need for renal replacement therapy [4]. Both hemodialysis due to not being well-tolerated in hypotensive patients, and peritoneal dialysis due to ineffective solute clearance and inadequate ultrafiltration, are less preferred day by day in hemodynamically unstable patients $[14,15]$. Continuous renal replacement therapy has come into prominence and become frequently preferred method in the treatment of critical pediatric AKI patients in recent years due to its advantages of slow and continuous fluid removal and maintaining acid-base balance [16]. Acute kidney injury is a frequently observed clinical status in critical pediatric patients in pediatric intensive care units. When AKI is detected in a patient, the clinician must first consider the cause and apply appropriate treatment for the cause. Dehydration and reduced renal perfusion are the most common causes of AKI, followed by drug and nephrotoxin-associated AKI [17]. Factors such as sepsis, critical disease, cardiopulmonary bypass, major noncardiac surgeries, mechanical ventilation, vasopressor use, extracorporeal membrane oxygenation are the factors that increase the risk of AKI in pediatric intensive care units [18]. Choi et al. [19] in their 6-year retrospective study involving 123 patients have reported that the most common cause of AKI was sepsis/septic shock with a rate of $38.2 \%$ [19]. Similarly, in our study, the most common cause of AKI was sepsis (38.5\%).

The most common indication for CRRT in pediatric intensive care units is hypervolemia and the appropriate treatment of fluid overload is critical [20]. Fluid overload leads to an increase in the preload of the heart, causing pulmonary congestion. In connection with this, an increase occurs in the need for mechanical ventilation, intensive care stay time, and mortality $[21,22]$. In the report of a multicentre, prospective pediatric CRRT (ppCRRT) study group, which included 344 patients between the ages of neonates and 25 years and whose body weights ranged from 1.3 to $130 \mathrm{~kg}$, the most common indication for CRRT has been stated to be the fluid electrolyte imbalance [23]. The relationship between increased fluid overload percentage and the poor clinical course has been previously shown in many adults and pediatric studies $[24,16]$. Treatment management in patients with acute renal injury, oliguria, and fluid overload is still unclear. In the first step of the treatment, especially loop diuretics are used. Renal replacement therapy should be applied in cases which are unresponsive to diuretic therapy and have increased fluid overload. It is known that the clinical course of patients receiving RRT in the early period is better [25]. Also, in our study, the most frequent indication for CRRT was found to be fluid overload. In one study, it has been shown that each $1 \%$ increase in fluid overload would cause a $3 \%$ increase in mortality. In the same study, patients with $>20 \%$ fluid overload have been found to have longer ICU stay time, more multiple organ failures and sepsis, higher inotrop support and higher PRISM II score compared to the patients with $<10 \%$ fluid overload [26]. In our study, the mean fluid overload percentage was $9.05 \pm 4.98$, and there was no significant difference between the group with mortality and the group without mortality in terms of fluid overload percentage. However, VIS was significantly higher in the group with mortality. AKI is a significant reason of mortality in critical pediatric patients [2]. The mortality rate of acute kidney injury has been reported to be between 39\% and $44.7 \%$ at various studies $[3,10,27]$. In one study, the mortality rate had been reported as $42 \%$ [23]. In our study, the mortality rate was $15.4 \%$. In a study in the literature, increased mortality rates have been reported in patients with a period longer than 5 days between admission to ICU and start of CRRT [19]. Also, our results showed that mortality increased as the time between hospitalization in ICU and CRRT start increased.

The factors associated with poor clinical course in patients receiving CRRT have been identified in several studies. High PRISM III score and VIS, and similarly the need for mechanical ventilator 
support, have also been reported like risk factors for increased mortality $[28,29]$. In our study, we did not find any difference between the mortality and non-mortality groups in terms of PRISM III score; however, in the mortality group, VIS was significantly higher, and we determined that as VIS increased, mortality increased. Bagshaw et al., [30] have reported a lower mortality rate in patients with serum creatine level of $3.5 \mathrm{mg} / \mathrm{dL}$ [30]. Choi et al., [19] have found that serum creatine level was significantly lower in the mortality group. The authors interpreted this as the increase in serum creatine is a warning factor for the clinician and leads to the start of CRRT in the early period [19]. In our study, serum creatine level was lower in the mortality group, but there was no detected statistical significance. Catheter location and size are very important factors in CRRT efficacy. In general, short and thick catheters are associated with longer filter life because they allow higher blood flow rates [31]. Femoral vein, internal jugular vein and subclavian vein are preferred as locations for the catheter. When selecting the catheter location, infections, thrombosis, stenosis, and circulatory conditions should be considered. While the femoral vein is used 3 times more frequently than the internal jugular vein and subclavian vein, the internal jugular vein has been reported to be associated with better filter life [32]. Since the use of subclavian vein can cause stenosis, it should be avoided. In the data of the prospective pediatric CRRT study group, catheter location has been reported as femoral vein with a rate of $73 \%$ [23]. Although there are studies suggesting that there is an assumption that the risk of infection is generally higher in femoral catheters [33], the only randomized controlled study comparing bacteraemia and colonization rates between hemodialysis catheters placed in femoral and internal jugular veins has shown no significant increase in femoral vein colonization rate, and the catheter-related blood flow infection rates have been reported to be similar [34]. Furthermore, in the recommendation guideline for renal replacement treatment in adult and pediatric intensive care units of the French dialysis group, there is a strong suggestion that the femoral vein and right internal jugular vein are equal in terms of the infectious complications [35]. In the same guideline, it has been recommended to use the right internal jugular vein most frequently [35]. In our study, the most common catheterization site was internal jugular vein (73\%).

Continuous venovenous hemodialysis diffusion and CVVHDF are modalities working with the principles of diffusion and convection. In the last report of the ppCRRT study group reporting data from 13 centres in the United States, CVVHD use has been reported as $48 \%$ and CVVHDF use as $30 \%$ [23]. It has been reported that the modalities working with convection principle are more preferred in Europe [36]. As a result, modality selection in CRRT should be done according to the needs of the patient, although it depends on the central attitude in general. In a study showing a 3-year CRRT experience of a pediatric intensive care unit in Turkey, the most common CRRT modality has been reported as CVVHDF [37]. Especially in septic patients, CVVH is a preferred modality in the clearance of medium-large molecular weighted solutes such as inflammatory mediators [38]. The results of our study showed that CVVHDF was applied at a rate of $96 \%$ in our clinic. We attributed this to the fact that sepsis was the most common reason of AKI in our patient group and that we had chosen the appropriate modality.

Anticoagulation is necessary to ensure the continuity of extracorporeal circulation. Systemic anticoagulation with heparin or regional with citrate may beperformed. Systemicanticoagulation with heparin is the most common method; however, care should be taken in terms of bleeding complications and heparin-induced thrombocytopenia. Citrate provides regional anticoagulation and is advantageous in terms of bleeding complications [31]. Although there are many adult studies comparing citrate and heparin, pediatric data is limited. Besides, in recent years, citrate anticoagulation has been preferred more frequently in the pediatric age group and the use of citrate anticoagulation has been reported with increasing frequency (56\%) in the data of the ppCRRT study group [23]. The results of a prospective, fiveyear study evaluating 63 children aged 0-18 years has shown that citrate anticoagulation provides significantly longer filter life and the authors have stated that citrate can be used safely in children and infants [33]. In our study, anticoagulation with heparin was applied to $14(54 \%)$ patients. In the group in which heparin was used as an anticoagulant, the filter life was longer and filter number was lower. During the study period, since there was no liquid suitable for anticoagulation with citrate in our centre, citrate could not be used. However, we observed a significant improvement in filter life with the increased use of citrate in our clinic lately. Disadvantages of CRRT include the requirement for technical expertise, the need for anticoagulation, and the need for close monitoring of the hemodynamic and coagulation parameter $[39,40]$. The most important limitation of our study was the low number of patients. Although our sample size was not suitable for performing multivariate analysis affecting mortality, our aim was to evaluate the etiology of AKI and CRRT applications over 18 months period of CRRT experience. In conclusion, CRRT is preferred more frequently in the treatment of AKI in critical pediatric patients due to its efficacy and safe use. Especially in critical pediatric patients with fluid overload and in need of multiple inotropes, we believe that application of CRRT in the early period will be lifesaving.

\section{References}

1. Williams DM, Sreedhar SS, Mickell JJ, Chan JC (2002) Acute kidney failure: A pediatric experience over 20 years. Arch Pediatr Adolesc Med 156(9): 893-900.

2. Warady BA, Bunchman T (2000) Dialysis therapy for children with acute renal failure: Survey results. Pediatr Nephrol 15(1-2): 11-13.

3. Hayes LW, Oster RA, Tofil NM, Tolwani AJ (2009) Outcomes of critically ill children requiring continuous renal replacement therapy. J Crit Care 24(3): 394-400.

4. Rewa O, Bagshaw SM (2014) Acute kidney injury-epidemiology, outcomes and economics. Nat Rev Nephrol 10(4): 193-207.

5. Ronco C, Bellomo R (1998) Critical care nephrology. 
6. Jones CH, Richardson D, Goutcher E, Newstead CG, Will EJ, et al. (1998) Continuous venovenous high-flux dialysis in multiorgan failure: a 5-year single center experience. Am J Kidney Dis 31(2): 227-33.

7. Goldstein SL (2011) Continuous renal replacement therapy: Mechanism of clearance, fluid removal, indications and outcomes. Curr Opin Pediatr 23(2): 181-185.

8. Legrand M,Darmon M, Joannidis M, Payen D (2013) Management of renal replacement therapy in ICU patients: an international survey. Intensive Care Med 39(1): 101-108.

9. Prabhakaran P, Richter RP, Tofil NM (2017) Factors Associated With Mortality in Pediatric Acute Kidney Injury Treated With Continuous Renal Replacement Therapy: More Questions Than Answers. Pediatr Crit Care Med 18(2): 198-199.

10. Symons JM, Brophy PD, Gregory MJ, McAfee N, Somers MJ, et al. (2003) Continuous renal replacement therapy in children up to $10 \mathrm{~kg}$. Am J Kidney Dis 41(5): 984-989.

11. John A Kellum, Norbert Lameire, Peter Aspelin, Rashad S Barsoum, Emmanuel A Burdmann, et al. (2012) Kidney Disease: Improving Global Outcomes (KDIGO); Acute Kidney Injury Work Group: KDIGO clinical practice guidelines for acute kidney injury. Kidney Int Suppl 2(1) 1-138.

12. Goldstein SL, Currier H, Graf Cd, Cosio CC, Brewer ED, et al. (2001) Outcome in children receiving continuous venovenous hemofiltration. Pediatrics 107(6): 1309-1312.

13. Gulla KM, Sachdev A, Gupta D, Gupta N, Anand K, et al. (2015) Continuous renal replacement therapy in children with severe sepsis and multiorgan dysfunction-A pilot study on timing of initiation. Indian J Crit Care Med 19(10): 613-617.

14. Wu VC, Huang TM, Shiao CC, Lai CF, Tsai PR, et al. (2013) The hemodynamic effects during sustained low-efficiency dialysis versus continuous veno-venous hemofiltration for uremic patients with brain hemorrhage: a crossover study. J Neurosurg 119(5): 1288-1295.

15. Daniela Ponce, Marina Berbel Buffarah, Cassiana Goes, Andre Balbi (2015) Peritoneal dialysis in acute kidney injury: trends in the outcome across time periods. PLoS One 10(5): e0126436.

16. Sutherland SM, Zappitelli M, Alexander SR, Chua AN, Brophy PD, et al (2010) Fluid overload and mortality in children receiving continuous renal replacement therapy:The prospective pediatric continuous renal replacement therapy registry. Am J Kidney Dis 55(2): 316-325.

17. Chawla LS, Goldstein SL, Kellum JA, Ronco C (2015) Renal angina: concept and development of pretest probability assessment in acute kidney injury. Crit Care 19: 93.

18. Basu RK, Zappitelli M, Brunner L, Wang Y, Wong HR, et al. (2014) Derivation and validation of the renal angina index to improve the prediction of acute kidney injury in critically ill children. Kidney Int 85(3): 659-667.

19. Choi SJ, Ha EJ, Jhang WK, Park SJ (2017) Factors Associated With Mortality in Continuous Renal Replacement Therapy for Pediatric Patients With Acute Kidney Injury. Pediatr Crit Care Med 18(2): 56-61.

20. Boschee ED, Cave DA, Garros D, Lequier L, Granoski DA, et al. (2014) Indications and outcomes in children receiving renal replacement therapy in pediatric inten- sive care. J Crit Care 29(1): 37-42.

21. Gillespie RS, Seidel K, Symons JM (2004) Effect of fluid overload and dose of replacement fluid on survival in hemofiltration. Pediatr Nephrol 19(12): 1394-1399.

22. Mitchell JP, Schuller D, Calandrino FS, Schuster DP (1992) Improved outcome based on fluid management in critically ill patients requiring pulmonary artery catheterization. Am Rev Respir Dis 145(5): 990-998.
23. Symons JM, Chua AN, Somers MJ, Baum MA, Bunchman TE, et al. (2007) Demographic characteristics of pediatric continuous renal replacement therapy: a report of the prospective pediatric continuous renal replacement therapy registry. Clin J Am Soc Nephrol 2(4): 732738.

24. Hayes LW, Oster RA, Tofil NM, Tolwani AJ (2009) Outcomes of critically ill children requiring continuous renal replacement therapy. J Crit Care 24(3): 394-400.

25. Zarbock A, Kellum JA, Schmidt C, Van Aken H, Wempe C, et al. (2016) Effect of early vs delayed initiation of renal replacement therapy on mortality in critically Ill patients with acute kidney injury:The ELAIN randomized clinical trial. JAMA 315(20): 2190-2199.

26. Sutherland SM, Zappitelli M, Alexander SR, Chua AN, Brophy PD, et al (2010) Fluid overload and mortality in children receiving continuous renal replacement therapy: the prospective pediatric continuous renal replacement therapy registry. Am J Kidney Dis 55(2): 316-325.

27. Foland JA, Fortenberry JD, Warshaw BL, Pettignano R, Merritt RK, et al. (2004) Fluid overload before continuous hemofiltration and survival in critically ill children: A retrospective analysis. Crit Care Med 32(8): 1771-1776.

28. Fernández C, López-Herce J, Flores JC, Galaviz D, Rupérez M, et al. (2005) Prognosis in critically ill children requiring continuous renal replacement therapy. Pediatr Nephrol 20(10): 1473-1477.

29. Bresolin N, Silva C, Halllal A, Toporovski J, Fernandes V, et al. (2009) Prognosis for children with acute kidney injury in the intensive care unit. Pediatr Nephrol 24(3): 537-544.

30. Bagshaw SM, Uchino S, Bellomo R, Morimatsu H, Morgera S, et al (2009) Timing of renal replacement therapy and clinical outcomes in critically ill patients with severe acute kidney injury. J Crit Care 24(1): 129-140.

31. Cho MH, Kang HG (2018) Acute kideny injury and continuous renal replacement therapy in children; what pediatricians need to know. Korean J Pediatr 61(11): 339-347.

32. Hackbarth R, Bunchman TE, Chua AN, Somers MJ, Baum M, et al (2007) The effect of vascular access location and size on circuit survival in pediatric continuous renal replacement therapy: a report from the PPCRRT registry. Int J Artif Organs 30(12): 1116-1121.

33. Zaoral T, Hladík M, Zapletalová J, Trávníček B, Gelnarová E (2016) Circuit Lifetime With Citrate Versus Heparin in Pediatric Continuous Venovenous Hemodialysis. Pediatr Crit Care Med 17(9): 399-405.

34. Parienti JJ, Thirion M, Mégarbane B, Souweine B, Ouchikhe A, et al (2008) Femoral vs jugular venous catheterization and risk of nosocomial events in adults requiring acute renal replacement therapy: a randomized controlled trial. JAMA 299(20): 2413-2422.

35. Vinsonneau C, Allain-Launay E, Blayau C, Darmon M, Ducheyron D, et al. (2015) Renal replacement therapy in adult and pediatric intensive care: Recommendations by an expert panel from the French Intensive Care Society (SRLF) with the French Society of Anesthesia Intensive Care (SFAR) French Group for Pediatric Intensive Care Emergencies (GFRUP) the FrenchDialysis Society (SFD). Ann Intensive Care 5(1): 58.

36. de Galasso L, Emma F, Picca S, Di Nardo M, Rossetti E, et al. (2016) Continuous renal replacement therapy in children: fluid overload does not always predict mortality. Pediatr Nephrol 31(4): 651-659.

37. Ricci Z, Goldstein SL (2016) Pediatric continuous renal replacement therapy. Contrib Nephrol 187: 121-130.

38. Sık G, Demirbuga A, Günhar S, Nisli K, Citak A (2019) Clinical Features and Indications Associated With Mortality in Continuous Renal Replacement Therapy for Pediatric Patients. Indian J Pediatr 86(4): 360364. 
39. Sinha R, Sethi SK, Bunchman T, Lobo V, Raina R (2018) Prolonged inter mittent renal replacement therapy in children. Pediatr Nephrol 33(8) 1283-1296.
40. Rajit K Basu, Derek S Wheeler, Stuart Goldstein, Lesley Doughty (2011) Acute renal replacement therapy in pediatrics. Int J Nephrol 2011.

Your next submission with Juniper Publishers will reach you the below assets

- Quality Editorial service

- Swift Peer Review

- Reprints availability

- E-prints Service

- Manuscript Podcast for convenient understanding

- Global attainment for your research

- Manuscript accessibility in different formats

( Pdf, E-pub, Full Text, Audio)

- Unceasing customer service

Track the below URL for one-step submission

https://juniperpublishers.com/online-submission.php 